\title{
Measurement Model of Hospital Performance for Achieving Hospital Mission in Indonesia
}

\author{
Budi Hartono ${ }^{1}$, Amal C. Sjaaf ${ }^{2}$, Adang Bachtiar ${ }^{3}$, Purnawan Junadi ${ }^{4}$ \\ ${ }^{1}$ Department of Public Health, Hang Tuah Health Sciences Institute, Indonesia \\ coachbuton@gmail.com \\ ${ }^{2,3,4}$ Departement of Health Administration \& Policy, Faculty of Public Health, University of Indonesia, Indonesia \\ amal.c.sjaaf@gmail.com \\ adang@jhu .edu \\ pije01@gmail.com
}

\begin{abstract}
Performance measurement is an important issue. This reminds that healthcare industry characteristic is unique rather than others. Health care with its all activities is a "high risk" industry. Performance measurement is the centre of quality improvement. From this, many factors or reasons related to excellent services can be identified. This research aimed to get quality dimensions that could be used as performance measurement in hospital as a health care provider. The direction of this performance measurement is as guidance on achieving hospital mission. With limited resources, Hospital needs priority to achieve its mission, so its need to be known wisely the critical dimension that correlate to a hospital mission. The design of this research was an operational research that using both qualitative and quantitative method in the government and private hospital in Indonesia. The result showed that there is a correlation between Patient Centeredness dimension with Clinical Effectiveness, Efficiency, Staff Orientation, Responsive Governance and Design dimensions, where all of dimension (except Responsive Governance) showed a positive correlation to the hospital mission variable. Hereby its correlation of equation: Hospital Mission = 0.118 Clinical Effectiveness + 0.348 Efficiency - 0.034 Responsive Governance + $\mathbf{0 . 1 8 2}$ Staff Orientation $+\mathbf{0 . 2 6 8}$ Design. Where the influence of Patient Centeredness dimension to Clinical Effectiveness is about 0.578 , Efficiency is about 0.488 , Staff Orientation is about $\mathbf{0 . 4 7 8}$, Responsive Governance is about 0.609 and Design is about 0.351 . From structural model equation test with Partial Least Square was summarized that the big affluence dimension to the mission is Efficiency and Design, while Responsive Governance is not a critical dimension in this model due to it has a negative correlation to the mission. The model consists of quality dimensions for hospital performance on achieving hospital mission. This model is called Mission Achievement Tools in Hospital model (MATH). MATH model could be functioned as a management system, strategic management tools, and as a dashboard on hospital organization's trip to achieve the mission that can be used by The Ministry of Health to develop policy especially in hospital area.
\end{abstract}

Keywords - Performance Measurement, Hospital Mission, MATH Critical Model

\section{INTRODUCTION}

World Health Report 2000 identified that hospitals play an important role in achieving health
[21]. It stated that the functions of hospital are to provide complex curative care which depend on its institutional capacity, to act as first/second/third/last referring facility, to provide emergency care for critical disease, as a centre of knowledge and skill transfer, as an information and strength resources, and also hospital become an institution that spends much part of the national health resources, it is about $50-80 \%$ from national health expenditures.

In Indonesia, global health care competition strict increasingly [24] especially in universal coverage era and the enactment of Asian Economic Community, to be exist, customer or patient satisfaction in hospital would be the main strategy for health services organization. It can become a challenge and a strategic issue for hospital sustainability as a public institution in the future.

Achieving goals or mission for hospital is not easy [19], it is also due to the characteristics of hospital industrial is 'unique' compared with other industries. High hazard is one of the uniqueness in health care industry by their actions (1). The report from Institute of Medicine states that each year about 44000-98000 patients died in the United States as a result of medical errors that occur in health care centres. In many other developed countries such as the UK, Denmark and Australia found the incident is not expected to range from $3.2 \%$ to $16.6 \%$. Meanwhile in Indonesia, is also assumed to be too large and some experts believe that it takes more research in order to assess the magnitude of the problem [7]. This quality issues are a challenge for hospital mission achievement. 
Achievement of hospital mission often has problems because the idea of measuring the trend of general hospital performance nationally has been slow and slowly run towards its mission. Measurement is the weakest area in the current management. From several studies suggested that approximately $80 \%$ of large companies in the US want to change their performance measurement systems. Survey on performance measurement conducted in 2001 states that 7 out of every 10 organizations are feeling dissatisfied with their measurement efforts [12]. Performance measurement for hospital have not been satisfactory because of incomplete or easily influenced by pressure or both, and measurements can create a focus on the future [14] so it can evaluate how well the organization were managed and delivered value for stakeholders [12].

In the era of National Health Insurance (Jaminan Kesehatan Nasional or JKN), Healthcare system in Indonesia does not consistently yet provide safe and effective services, and also not afford to compete with hospital abroad, it will be seen from the growth of patient who look for hospitalization in abroad and low of trust [23]. Preliminary study found that hospital dissatisfied with the performance measurement tool used because it does not cover all existing dimension as overly focus on the financial aspect, too general and not touching aspects of operations in accordance with the characteristics of health care, so it makes that performance measurement is not comprehensive yet. Researchers found no tools of measuring instruments yet used by hospitals when achieving missions in order to fulfil the mandate of the law [17]. WHO desired recommendations to make a uniform in the hospital performance measurement tools, so all the repaired, upgraded and maintained aspects can be mapped nationally. It becomes easier for the government as a regulator to control and monitor the hospital institutions because they have the same measuring tools and ease in benchmarking against best practices performed by hospital on an international scale. Associated with this background, this study aimed to develop a Hospital Performance Measurement Model To Achieve Hospital Mission that fit to the dynamics conditions for hospital in Indonesia.

\section{METHOD}

This is an operational research using qualitative and quantitative approaches. Conducted on the year of 2010, this research has two phases where the first phase is a qualitative research consists of exploratory literature, informants practitioners, and document study to get constructs model where the framework concept will come from Performance Asessment Tool for Quality Improvement in Hospital (PATH), USA Joint Commission and The Balanced Scorecard [12], [20], [22]

The second phase is a quantitative study with confirmatory approach towards a fixed model. The sample of this research involved 25 hospitals that comes form the Government General Hospital and private with the classification of class B hospital in Indonesia. The purposes of this research is to get quality indicators of hospital performance.

Data analysis was performed for all variables measured and performed to test the lines of the model constructs by using Sequent equation Equation Model with Partial Leased Square program (PLS). Univariat, bivariat and multivariat analysis was conducted with a view to determine the frequency, distribution, correlation and the central tendency of conditions (variable) were observed.

This study is limited to the general hospital with class $\mathrm{B}$ regardless there are several hospitals with class C (+) plus hospital with local government and private ownership status or foundations. The unit analysis of this study were them who understand the scope of work the unit of the hospital, such as: General unit, Medical Services unit, Finance unit, Human Resources unit, Nursing unit, and hospital equipment maintenance unit where the head of unit would be conducted as an informant. Each section was classified into one composite, so this will give impact on the number of samples. Statistically, these samples go to the small sample category but still can be processed by using PLS smart program to produce model equation.

\section{RESULT AND DISCUSSION}

The test results of convergent validity can be seen on the outer models loadings (using the program package of Smart PLS) as shown below. 


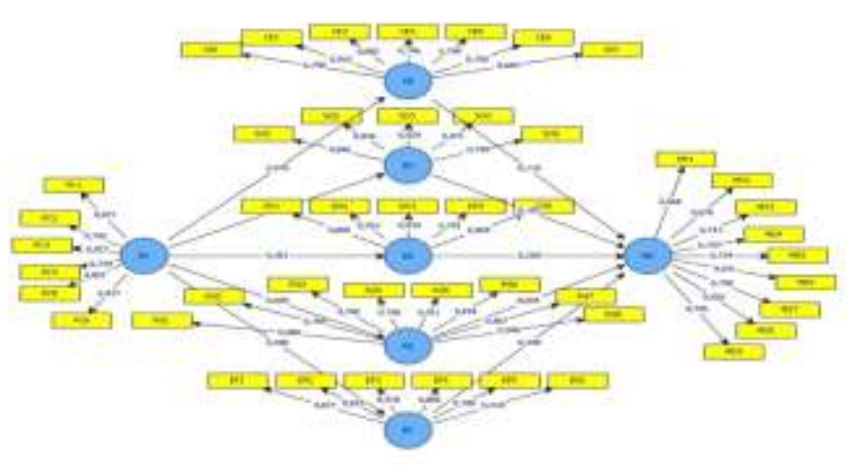

Fig. 1. Structural Equation Line Against Indicators on Each Latent Pilar

Based on the diagram above, coefficient parameters obtained by calculating $\mathrm{T}$-Stats value through bootstrap standard error of procedures and weighting the inner model. The assessment results of the of the $\mathrm{R}^{2}$ and parameter coefficient of hospital mission is as follows:

TABLE I

LINE OF PARAMETER COEFFICIENT

\begin{tabular}{lcccc}
\hline $\begin{array}{l}\text { Latent } \\
\text { Pillar }\end{array}$ & $\begin{array}{c}\text { Line of } \\
\text { Parameter } \\
\text { Coefficient }\end{array}$ & $\begin{array}{c}\text { Sampl } \\
\boldsymbol{e} \\
\text { Mean }\end{array}$ & $\begin{array}{c}\text { Stand } \\
\text { ard } \\
\text { Error }\end{array}$ & T-Statistik \\
\hline PC $\rightarrow$ CE & 0,578 & 0,615 & 0,080 & 7,215 \\
PC $\rightarrow$ EF & 0,488 & 0,540 & 0,132 & 3,695 \\
PC $\rightarrow$ RG & 0,609 & 0,641 & 0,117 & 5,186 \\
PC $\rightarrow$ SO & 0,478 & 0,461 & 0,094 & 5,085 \\
PC $\rightarrow$ DS & 0,351 & 0,411 & 0,154 & 2,285 \\
CE $\rightarrow$ MS & 0,118 & 0,098 & 0,288 & 0,408 \\
EF $\rightarrow$ MS & 0,348 & 0,389 & 0,235 & 1,480 \\
RG $\rightarrow$ MS & $-0,034$ & $-0,046$ & 0,257 & 0,132 \\
SO $\rightarrow$ MS & 0,182 & 0,163 & 0,111 & 1,628 \\
DS $\rightarrow$ MS & 0,268 & 0,298 & 0,129 & 2,074 \\
\hline
\end{tabular}

\begin{tabular}{cc}
\multicolumn{2}{c}{ TABLE II } \\
\multicolumn{2}{c}{ R-SQUARE } \\
\hline Pilar Laten & $\boldsymbol{R}$ Square \\
\hline CE & 0,334 \\
EF & 0.238 \\
RG & 0.371 \\
SO & 0.228 \\
DS & 0.123 \\
MS & 0.504 \\
\hline
\end{tabular}

$\mathrm{R}$ square value for Pillar of Clinical Effectiveness (CE) are about 0.334 means that variations of $\mathrm{CE}$ can be explained about $33.4 \%$ by Pilar of Patient centeredness $(\mathrm{PC})$ while the remaining $(66.6 \%)$ was influenced by the other pillar that is not contained in this research model. The $\mathrm{R}$ square valuefor Pillar of Efficiency $(\mathrm{EF})$ is about 0.238 means that variations in EF can be explained about $23.8 \%$ by Pillar of Patient centeredness (PC) and so on.

Based on estimation using the bootstrap sample of 50 cases per the original sample as many as 25 , the value of parameters coefficient for the structural model as follows:

1) Effect of Patient centeredness (PC) against Clinical Effectiveness (CE) is about 0.578 units with T-Stats value of 7.215. This means that the higher Patient centeredness (PC) the higher Clinical Effectiveness (CE), and it also the higher level of efficiency (EF), the higher the level of Responsive Governance (RG), the higher the level of Staff Orientation (SO), the higher level of Hospital Design (DS).

The influence of latent Pillar to Hospital Mission (MS) can be explained as follows:

1) Effect of Clinical Effectiveness (CA) to the hospital Mission (MS) amounted to 0,118 units with a value of TStats of 0.408 , means there is no significant effect between Pillar of Clinical Effectiveness (CE) against Pillar of hospital Mission (MS).

2) Effect of Efficiency (EF) of the hospital Mission (MS) amounted to 0,348 units with a value of 1,480 T-statistics, means that there is a significant positive effect between Pillar of Efficiency (EF) of the Pillar of hospital Mission (MS). This means that the higher level of efficiency (EF) the higher the level of hospital Mission RS (MS). And also the higher level of Staff Orientation (SO) the higher the level of hospital Mission (MS), the higher level of the hospital Design (DS) the higher level of hospital Mission (MS).

3) Effect of Responsive Governance (RG) to hospital Mission (MS) of -0.034 unit with T-Stats value of 0.132 , means there is no significant effect between Pillar of Responsive Governance (RG) and the Pillar of hospital Mission (MS). Negative coefficient value indicates that the relationship between the Responsive Governance and Hospital Mission (MS) is inversely which means an increase Responsive Governance (RG) causes a decrease of hospital Mission (MS).

\section{Pillar and Hospital Performance Indicators}

The results of bivariate analysis with Rank Spearman test: these indicator respectively has load value $>0,05$ and $\mathrm{T}$ stat $>1,96$, there is a very strong relationship between indicators of respect for patients and client orientation with pillars of Patient Centeredness. Client orientation has a very strong association between indicators of access to services $(0,79 ; 30,29)$, supportive environment $(0,82 ; 15,25)$, comprehensiveness of services $(0,80 ; 11,79)$, as well as information and patient empowerment $(0,81$; 
16,68) with pillars of Patient Centeredness, while the indicator continuity $(0,73 ; 12,27)$ with pillars of Patient Centeredness found a strong correlation. It was seen that the services provided at the hospital should use a values-oriented services to patients as a priority to improve patient safety and satisfaction of patients and staff, as well as eliminating the difference in quality of service to minorities, the poor, and mentally ill. Then note the barriers to patient and family ties, such as lack of health knowledge and personal desires and cultures [20].

Significant relationship was found between the sub-indicators of sectio caesaria level $(0,74 ; 15,99)$, prophylactic antibiotics $(0,91 ; 36,98)$, mortality $(0,88 ; 24,71)$, readmission $(0,79 ; 18,26)$, return to the $\operatorname{ICU}(0,79 ; 9,16)$, readmission day surgery $(0,79$; $8,46)$ and sentinel event $(0,66 ; 15,99)$ with pillar of Clinical Effectiveness, where the mortality has the strongest links with the pillars of Clinical Effectiveness at the correlation value of 0.928 (the lowest was Sectio Caesarea level with a correlation value of 0.732 ). It was a significant relationship for all the pillars from mutivariat analysis and valid (the indicator can reliably measure the construct). The clinical effectiveness was a dimension in which a hospital's performance in line with the current level of knowledge, appropriate competent and clinical service delivery, and achieving results (outcomes) expected to all patients. Based on the framework concept for its application in the hospital, then there are three suitable dimensions for this: the treatment process, the outcome, and the accuracy of treatment [22].

Strong relationship was found between the level of day surgery level $(0,87 ; 24,21)$, length of stay $\operatorname{LOS}(0,82 ; 12,03)$, the use of day surgery $(0,57$; $3,90)$, inventory stock $(0,88 ; 53,42)$, operating threat un-use session $(0,75 ; 11,93)$ and financial management $(0,41 ; 2,43$ : significant only) with Efficiency pillar. This shows that the indicators were strongly supports the establishment of the efficiency's pillars. WHO stated that efficiency is an indicator that measures the performance in assessment optimum use of inputs to produce the maximum output and provide available resources [22].

There is a strong relationship between the indicator of waiting times $(0,88 ; 30,08)$, access
$(0,70 ; 11,20)$, nursing mothers were at discharge $(0,78 ; 12,04)$, integration and continuity of service $(0,79 ; 18,23)$, equity \& ethic $(0,76 ; 15,13)$, environmental safety $(0,81 ; 14,86)$, technology $(0,86 ; 20,34)$, and partnerships $(0,60 ; 6,92)$ with pillars of Responsive Governance (indicators can reliably measure the construct). It is included Responsive Governance indicators as set by WHO [22].

There is a very strong association between indicators of absenteeism (0,84; 18,32), occupational accidents $(0,84 ; 23,98)$, excessive working hours $(0,82 ; 28,54)$, budget for health promotion staff $(0,87 ; 38,41)$, and leadership $(0,73$; $11,47)$ with pillars of Staff Orientation. With the highest correlation value is occupational accidents (0.922) while the lowest correlation with the leadership (0.769). Those indicators can reliably measure the construct for sub dimension of Staff Orientation [22].

There is a very strong relationship between indicators of safe design $(0,85 ; 17,82)$, priorities accommodation $(0,75 ; 6,71)$, flexibility design $(0,81$; 13,99), as well as the principle of optimality workflow $(0,75 ; 7,43)$ and supportive work climate $(0,80 ; 14,38)$ with pillar of Hospital Design, while the indicator of Green Hospital with hospital design in addition to have a strong relationship correlation as well. Indicators are used to form the construct. This is an indicator on the pillars of hospital Design [20].

Pillars of hospital mission with indicators of the mission, the results showed that the indicator of geographical service $(0,56 ; 4,74)$, priority segmentation $(0,67 ; 7,72)$, featured services $(0,74$; $7,54)$, embraced philosophy $(0,72 ; 8,94)$, efforts to mission $(0,73 ; 1370)$, stakeholders' expectation $(0,63 ; 7,02)$, sharing vision $(0,78 ; 10,54)$, public health orientation $(0,82 ; 23,32)$ and excellent service $(0,75 ; 9,35)$. These indicators can reliably measure the construct. This is in line with the mission statement must contain: 1) identifying the target customer and the market, 2) principal products / services, 3) domain region, 4) core technology, 5) commitment to the survival and profitability, 6) philosophic company, 7) the concept of self-company, 8) the company's public 
image that inspires, 9) concern for the staff, 10) clarity of statement [6].

\section{Performance Measurement Model Of Mission Achievement Tools In Hospital (Math)}

Model of performance measurement based on these results, was described below:

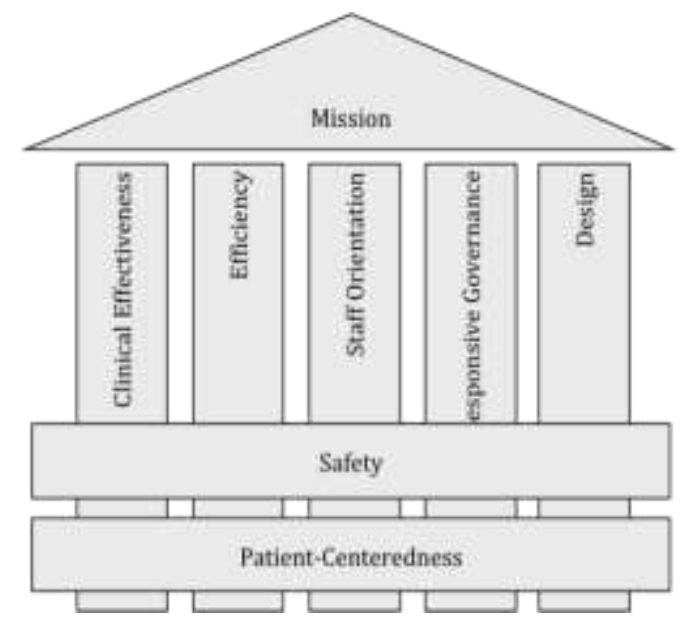

Fig 2. Mission Achievement Tools in Hospital Model (MATH)

MATH Model as hospital performance measurement model focuses on six pillars: Clinical Effectiveness, Efficiency, Staff Orientation, Design, Safety and Patient centeredness. The six quality pillars served as pillars in achieving the hospital Mission. Operationally, pillar of Safety on the MATH model is fused to the pillar of Clinical Effectiveness (Clinical Effectiveness and Patient Safety), Staff Orientation (Staff Orientation and Staff Safety), Responsive Governance (Responsive Governance and Environmental Safety), as well as implicitly melt pillar of Efficiency and Design.

\section{Implications Of Math Model As A Performance Measurement In Hospital}

Currently in Indonesia, most of the hospital performance measurement refers to accreditation by Hospital Acreeditation Commitee and the hospital minimum service standards (SPM), which is a measure or a standard that must be fulfiled by hospital minimally adapted to the resources owned. This makes each hospital has different standards because of capacity and coverage differencies. In general, MATH Model as a performance measurement model has the parameters used in the process of accreditation by Joint Commission
International mentioned above. So the implications for hospitals by using the MATH Model as a performance measurement is that the hospital has a management system modality that will support the accreditation process as well as has the ability to map outcome results of the accreditation process. Operational model in achieving the mission can be seen at the picture below:

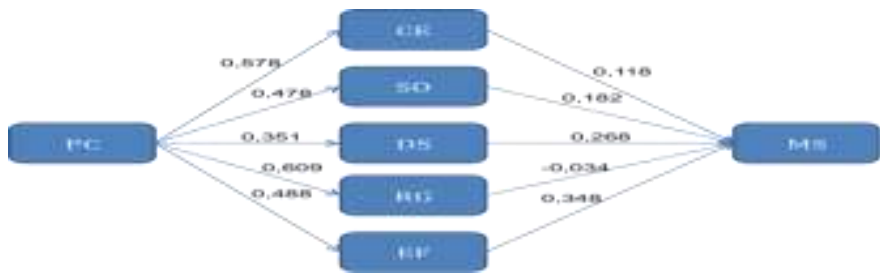

Fig 3.Correlation in Mission Achievement Tools in Hospital (MATH) Model

A. Patient Centeredness towards Clinical Effectiveness, Efficiency, Staff Orientation, Responsive Governance, Design

Patient centeredness is a dimension of performance where the hospital placed patient at the center of services by giving special attention to the needs of patients and their families, hopes, autonomy, access to a network that supports, communication, confidentiality, privilege, selection of the provider, the desire for the prompt, and treatment timely [22]. It must be seen that the services provided at the hospital should use a values-oriented services to patients as a priority to improve patient safety and patients and staff satisfaction, as well as eliminating the difference in quality of services to minorities, the poor, and mentally ill, as well as notes obstacles to patient and family ties, such as lack of knowledge of health and personal preferences and culture [22].

The higher level of Patient centeredness the higher level of Clinical Effectiveness will be, so the hospital should be able to describe how the mortality can be monitored and how the key outcome and process indicators are used in a process of quality improvement. The strategy should include profiling of medical personnel, peer review analysis of mortality by the Committee and the internal Committee. [22].

The higher level of Patient Centeredness the higher level of Efficiency will be. Implications for hospital is Day surgery has become a priority area 
for reforming of hospital in recent years. On day surgery indicator is putting forward in terms of cost efficiency and optimal capacity utilization. The hospital must continue to improve performance, especially on the service day surgery to improve quality, among which making strategies on investment equipment and facilities, operating rooms (operating list) that are intended for day surgery, improving coordination with home care agency, and the provision of hotel facilities hospital for patients who live far from the hospital [22].

Pillar of Patient centeredness against Pillar of Staff Orientation has a positive significant, so the hospital must pay attention to aspects of absences that have a relationship with the staff orientation. It cannot be separated because they relate to the performance of the hospital in particular on existing staff. Absences showed the failure of its staff to report when they have to work. For quality improvement strategies was addressing health problems of employees and increased motivation on the job [22].

Pillar of Patient centeredness towards Responsive Governance has a significant effect, so the hospital need to response to community needs, ensure sustainable and coordinated services, health promotion, innovative, and provide treatment to all people regardless of characteristics (race, physical, cultural, social, demographic and economic). Quality strategies are the information must be transparent and independent, keeping a waiting list, not a long waiting times, health promotion for specific patient category, the use of technology to monitor patients outside the hospital, a serviceoriented geriatrics, patient management who will discharge, better waste management, energy and water management effectively, build partnerships with other organizations [22]

The higher level of Patient centeredness the higher level of hospital Design will be, so the hospital need to prioritize efforts infection control and emergency preparedness in designing and building hospital, technology as well as the principle of "green" in design and construction of the hospital so that it can improve patient safety and can speed up the healing process for patients in hospital [20].
B. Patient Centeredness, Clinical Effectiveness, Efficiency, Staff Orientation, Responsive Governance, Design toward Hospital Mission.

Mission statement from various hospitals suggested that hospital mission generally led to excellent services that affordable for patients with emphasis on quality in accordance with hospital competency featured and met the expectations of stakeholders. From patient centeredness to Hospital Mission can be explained as follows:

1) Effect of Clinical Effectiveness to Hospital Mission. It is principle of putting patients at the focus of service and followed by a treatment technique that is seen from the precision of the treatment, the suitability of the treatment process and the results of the process of treatment and patient safety, the course will steer this service on the achievement of Hospital Mission mainly to concept aspects of self-enterprise services orientation led to excellent service and clarity statement service where the service-oriented to make people healthy. [22, 9]

2) There is a positive significant impact on the Pillar of Efficiency and Pilar of Hospital Mission.

Hospitals were required to streamline the service that fulfil safety element, to optimize the efforts of training for medical personnel and nurses, investment for high costs equipment and facilities services such as operating rooms, the amenities of home lay over for patients who live far from the hospital, clinical pathways, internal coordination of medical services in hospitals, reduction of delivery time cyle by suppliers, more efficient use of materials to reduce the buying back phenomenon as well as monitored the use of the operating room. This hospital effort will certainly bring to hospital mission achievement, especially in the image aspect of the public where the hospital services in accordance with stakeholders expectation, self-concept of company to excellent service, commitments related to the seriousness of achieving the mission as well as the norms and philosophy [22, 9]

3) There is a positive significant effect between Pilar Staff Orientation to Hospital Mission.

Staffs were required to have adequat qualification in providing needed services, have the opportunity to continuous learning $\&$ training, working in a positive condition, as well as having the satisfaction on their work. Hospital must facilitate the various efforts of staff orientation. So it will be able to get hospital closer to the mission achievement in the context of concern for staff where there are efforts to meet the stakeholders expectations as well as the commitment to continue achieving the mission $[9,20,22]$

4) There is a negative influence among Pillar of Responsive Governance to the Hospital Mission. 
Responsive Governance is a level where hospital respons to community needs, sustainable service guarantee, health promotion, innovative, and provide treatment to all people regardless of characteristics (race, physical, cultural, social, demographic and economic [22]. Among respondents had a high disparity in perceiving the hospital services (which have an impact on the variation of the distribution of the data). Although the relationship is negative, the pillar of Responsive Governance remains incorporated into the MATH Model (because the pillars and its indicators are valid and reliable in building the construct), but was not considered as a critical pillars in the model.

5) There is a positive significant effect between Pillar of Hospital Design againts Hospital Mission.

Hospital seeks to redesign the hospital design towards more appropriate function so it can accommodate infection control, management of noise, the readiness of emergency, workflow effective staff, design flexibility in capturing the rapid innovation of drugs and technology and green design aspects [22]

It is principle, putting patients at the centre of services by optimizing clinical function in an effective and efficient service, well managed staff orientation and maintain the design aspects of the hospital to maintain compliance function, it reflects accountability hospital, which the hospital as an organization of health care providers for public service institutions which its implementation must be in accordance with had been mandated by the Law No. 25/2009 about Public Service. This law based hospital should realize to: general interest, legal certainty, equal rights, rights and obligations balance, professionalism, participation, equality of treatment (non-discriminatory), openness, accountability, facilities and special treatment for vulnerable groups, punctuality, speed-easeaffordability. Implementation of this actually can give benefit as much as possible for humanity in order to maintain and improve the public health degree [24].

\section{MATH Critical Model as Strategic Planning tools in Hospital}

Hospital can use MATH Critical Model as a Strategic Planning tools to achieve hospital mission. Strategy should be focused on two critical pillars: 1) Efficiency such as cost efficiency and optimal capacity utilization [22], and 2) Hospital Design such as environmental dimension and the physical design to patient safety orientation and patient views of the spatial characteristics and design, green principles, groove and hospital staff accommodation. There are several things that need attention to achieve that Hospital design [20].

The correlation of equation is: Hospital Mission = 0.118 Clinical Effectiveness +0.348 Efficiency 0.034 Responsive Governance +0.182 Staff Orientation + 0.268 Design. The pillar of Efficiency and Design is more likely to be concentrated to the private hospital, it can be interpreted that private hospitals have the ability to achieve the mission faster than the government hospital.

\section{CONCLUSION}

Private hospitals are more focused on the pillars of Efficiency and Design, while the government hospital had perfection in the mission aspect. The pillars of quality that can be used, as a measure of performance are Patient Centeredness, Clinical Effectiveness, Efficiency, Staff Orientation and Design.

Critical pillars that can be used as a strategic focus for planning improvements in performance and hospital mission achievement are 1) Pillar of Efficiency; 2) Pillar of Design, 3) Pillar of Staff Orientation and 4) Pillar of Clinical Effectiveness, and Efficiency will be the most critical pillar

Mission Achievement Tools in Hospital (MATH) will be a tool for measuring the performance of hospital comprehensively with a broad spectrum of critical pillar recommends as a main focus of the strategy and also can be used as a hospital management system and tools for hospital strategic planning especially in the era of National Health Insurance.

\section{ACKNOWLEDGMENT}

We wish to acknowledge hospitals and other contributors who helped us to develop this model, so overall class B hospital in Indonesia can use to measure their performance, make a strategic plan and manage their system.

\section{REFERENCES}

[1] Barach, Paul, Hospital Design Promoting Patient Safety, American Society for Healthcare Engineering International Conference, San Diego, 2006

[2] Bocci, Fabrizio," Defining Performance Measurement", Bocc Consulting, Published On PMA Newsletter, Perspectives On Performance, Vol 3, Issue 1/2, Sept. 2004 
[3] Kementerian Kesehatan RI, Profil Kesehatan Indonesia, 2013 and 2014

[4] Ghozali, I., Structural Equation Modeling Metode Alternatif dengan Partial Least Square (PLS), Universitas Diponegoro, 2006

[5] Hindle, Donald, Patient Safety Research, a review of the technical literature, Center for clinical governance research, University of New South wales, Sidney NSW 2005.

[6] Horvat, Jelena, Exploring the Quality of Mission Statements on Croatia's Corporate Websites, 2010

[7] Institute of Medicine, Crossing the quality chasm: a new health system for the 21st century, Washington: National Academy Press, 2001

[8] IOM, Performance Measurement; Accelerating Improvement, Pathways to Quality Health Care, The National Academies Press, Washington DC, 2006

[9] J. Veillard, F. Champagne, N. Klazinga, V. Kazandjian, O. A. Arah And A.-L. Guisset," A Performance Assessment Framework For Hospitals: the WHO regional office for Europe PATH project", International Journal for Quality in Health Care 2005; Volume 17 , Number 6: pp. 487-496, Advance Access Publication: 9 September 2005

[10] JCI, Join commission accreditation standard for hospital, The joint commission on accreditation of healthcare organization, 2002

[11] Joel Zimmerman, Phd, "Using A Balanced Scorecard In A Nonprofit Organization", Journal Of Business \& Economics Research September 2008 Volume 6, Number 967

[12] Kaplan, R.S. and Norton, D.P, Transforming the Balanced Scorecard from Performance Measurement to Strategic Management: Part I, Accounting Horizons, Vol. 15 No. 1, March 2001, pp 87 - 104
[13] Kohn Linda T, Corrigan Janet, To Err Is Human: Building A Safer Health System, IOM, National Academies Press, 2000

[14] Lee, Nagarajah, "Measuring the performance of public sector organization: a case study on public schools in Malaysia", Measuring business excellent, Emerald group publishing limited, vol. 10 no. 4, 2006

[15] Niven Paul R, Adapting The Balanced Scorecard To Fit The Public And Nonprofit Sectors, Primerus Consulting, April 22, 2003

[16] Persi, Pedoman Pelaporan Insiden Keselamatan Pasien, KKP-RS Jakarta, 2007

[17] UU No. 44 tahun 2009 Tentang Rumah Sakit

[18] Scott, Graham, Dr., Hospital Productivity: How is it measured? What does it mean?, Business Roundtable, Media Release, 2008

[19] Sebastian Desmidt, "Towards a better understanding of the mission statement - performance relationship" Faculty Of Economics And Business Administration Dep. Of Management, Innovation And Entrepreneurship Ii, 2008

[20] The Joint Commission, Health Care At The Crossroads: Guiding Principles for the Development of the Hospital of the Future, 2008

[21] WHO, Europe, How can hospital performance be measured and monitored?, HEN, 2003

[22] WHO," Measuring Hospital Performance To Improve The Quality O Care In Europe: A Need For Clarifying The Concepts And Defining The Main Dimensions", Report On A Who Workshop Barcelona, Spain, 10-11 January 2003

[23] Adisasmito, Kesiapan RS Dalam Menghadapi Globalisasi, Case Study: Analisis Kebijakan, FKM UI, 2008 